\title{
Does it always feel good to get what you want? Young children differentiate between material and wicked desires
}

\author{
Craig E. Smith ${ }^{\prime} *$ and Felix Warneken ${ }^{2}$ \\ 'Department of Psychology, University of Michigan, Ann Arbor, Michigan, USA \\ ${ }^{2}$ Department of Psychology, Harvard University, Cambridge, Massachusetts, USA
}

\begin{abstract}
One line of research on children's attributions of guilt suggests that 3-year-olds attribute negative emotion to self-serving victimizers, slightly older children attribute happiness, and with increasing age, attributions become negative again (i.e., a three-step model; Yuill et al., 1996, Br. J. Dev. Psychol., 14, 457). Another line of research provides reason to expect that 3-year-olds may be predisposed to view self-serving moral transgression as leading to positive emotion; this is a linear developmental model in which emotion attributions to transgressors become increasingly negative over the course of childhood (e.g., Nunner-Winkler \& Sodian, 1988, Child Dev., 59, 1323). However, key differences in methodology make it difficult to compare across these findings. The present study was designed to address this problem. We asked how 3- to 9 -year-old children $(n=\mathrm{III})$ reason about transgression scenarios that involve satisfying wicked desires (wanting to cause harm and doing so successfully) versus material desires (wanting an object and getting it successfully via harmful behaviour). Three-year-old children reasoned differently about desire and emotion across these two types of transgressions, attributing negative emotion in the case of wicked desires and positive emotion in the case of material desires. This pattern of emotion attribution by young children provides new information about how young children process information about desires and emotions in the moral domain, and it bridges a gap in the existing literature on this topic.
\end{abstract}

Preschool-age children know that moral transgressions are wrong (e.g., Smetana, 1981) and that victims of transgressions feel bad (Arsenio \& Kramer, 1992; Smith, Chen, \& Harris, 2010). However, children younger than 7 often attribute positive feelings to protagonists who transgress in order to satisfy desires. For example, 4- to 6-year-old children frequently attribute happiness to characters who have obtained things like candy and toys via stealing or aggression (Arsenio \& Kramer, 1992; Nunner-Winkler \& Sodian, 1988; Smith et al., 2010). This phenomenon, termed the bappy-victimizer expectancy, is especially pronounced when young children attribute emotions to third-party transgressors, compared with the self-as-imagined transgressor (Keller, Lourenço, Malti, \& Saalbach, 2003). Across much of the research in this area, there is support for a two-step developmental progression, with 4 - to 6-year-olds attributing happiness to self-serving transgressors and 8- to 9-year-olds attributing mixed or negative emotions

*Correspondence should be addressed to Craig E. Smith, Department of Psychology, University of Michigan, 530 Church Street, Ann Arbor, MI 48103, USA (email: 999craig@gmail.com). 
(e.g., Arsenio \& Kramer, 1992; Keller et al., 2003; Nunner-Winkler \& Sodian, 1988; though see Murgatroyd \& Robinson, 1993).

It has been proposed that when attributing emotion to people who have satisfied material desires via transgression, children younger than 7 tend to focus on gains and have difficulty thinking about a victim's experience as influencing a victimizer's emotions (Arsenio, Gold, \& Adams, 2006). Older children, on the other hand, are more likely to simultaneously consider the gains of the transgressor and the transgression itself and are therefore more likely to predict guilty or mixed emotions in a transgressor (Arsenio \& Kramer, 1992). Young children's tendency to attribute solely positive emotion may also be linked to limitations in their cognitive ability to process and attribute two opposing emotional states (Harris, 1989; Wintre \& Vallance, 1994).

There is also empirical support for a model suggesting a 3-step developmental progression when children are asked to attribute emotion to transgressors who have satisfied desires. Yuill, Perner, Pearson, Peerbhoy, \& van den Ende (1996) interviewed children as young as 3 about situations in which a person transgressed in order to satisfy a wicked desire. For example, a protagonist wanted to push a child off a bike and the child was hurt in the fall. Yuill et al. found that 3-year-olds were prone to viewing transgressors in these wicked-desire (WD) scenarios as feeling sad. The 5- to 7-year-olds were more likely to attribute positive emotions to the transgressor, and by age 10, children attributed guilt to the transgressor. Yuill et al. proposed that 3-year-olds view desirability as an objective property that describes objects and events. Shortly after age 3, the authors suggested that children come to view desirability as a subjective phenomenon that exists at the meeting of a mind and an object/event (e.g., 'I don't like causing harm, but John does'). Thus, Yuill et al. argued that 3-year-olds view successful transgressors as feeling bad because they view transgressions and bad intentions as objectively unpleasant.

Two methodological approaches differentiate the Yuill et al. (1996) study from the related studies cited above: The types of desires studied and the ages of the children studied. Regarding the issue of desires, we note that Yuill et al. (1996) only used stories involving wicked desires (WD), while most other studies of the happy-victimizer expectancy use material-desire (MD) stories in which a protagonist causes harm as a means to an end (e.g., pushing to get a playground swing).

Regarding the issue of age, we note that the main body of research on the happy-victimizer expectancy is populated by studies that have presented children ages 4 and older with MD scenarios (e.g., Arsenio \& Kramer, 1992; Keller et al., 2003; Lagattuta, 2005; Lourenço, 1997; Nunner-Winkler \& Sodian, 1988; Smith et al., 2010). As noted above, the key finding from this body of research is that children move, with increasing age, from anticipating happiness in successful transgressors to anticipating guilt. Only Yuill et al. (1996) have conducted interviews with children as young as 3 about situations in which a person transgressed in order to satisfy a desire.

The discrepancy of age groups and wicked-versus-material desires in the existing research leads to interpretive problems concerning the development of the happy-victimizer expectancy. For example, Yuill et al. noted that their findings clarified the existing literature on the happy-victimizer expectancy, overlooking the fact that most existing studies had focused on the satisfaction of material - not wicked - desires, and had not included children younger than age 4. Nunner-Winkler and Sodian (1988) did include both WD and MD stories, but the youngest children tested were 4 . These 4-year-olds attributed positive emotion to transgressors who satisfied both wicked- and material desires. 
The purpose of this study was to bring methodological consistency to these open questions about children's emotion attributions by interviewing children, ranging in age from 3 to 9, about both WD and MD scenarios.

Each participant saw two successful transgression stories:

1. Material-Desire Success: A transgressor wants a playground swing and pushes another child in order to successfully obtain it.

2. Wicked-Desire Success: A transgressor wants to push another child on the playground and does so successfully.

Based upon the two models described above, we tested two possible patterns of emotion attribution as a function of age: Linear and quadratic. We anticipated that a linear model would best fit the age-attribution association in the MD-success scenario. Young children begin to verbalize (Bartsch \& Wellman, 1995; Symons, Fossum, \& Collins, 2006) and understand (Rakoczy, Warneken, \& Tomasello, 2007; Wellman \& Liu, 2004) simple states of desire well before they explicitly talk about and understand cognitive states such as thoughts and beliefs. Furthermore, 2-year-olds make use of instrumental aggression to control desired objects (Hay, Hurst, Waters, \& Chadwick, 2011). Thus, we predicted that 3 -year-olds would link the use of aggression to happy feelings in the case of MD satisfaction, as these patterns of desire-related thought and behaviour are relatively age typical. Consistent with the existing body of work on the happy-victimizer expectancy, we predicted that the attribution of positive emotion in the MD-success story would decline in linear fashion with increasing age.

In contrast to our predictions regarding the MD-success scenario, we anticipated that a quadratic model would best fit the association between age and emotion attributions in the WD-success scenario. While toddlers and young preschoolers are known to use aggression to control resources, it is rare to hear a young child verbalizing a desire to simply hurt another person. As noted, Yuill et al. (1996) presented 3-year-olds with fictional protagonists who simply wanted to hurt others and did so successfully. The 3-year-olds reacted as if such a desire was objectively bad (or, perhaps, wildly foreign) and expected the protagonists to feel bad after their wicked desires had been fulfilled. We expected the same result to emerge in this study, and we also expected to replicate the finding that children, starting at age 4, would attribute relatively happier emotions in the WD-success story and that the oldest age group would be most inclined to attribute guilty feelings.

Children were also shown two scenarios in which characters tried but failed to use aggression to satisfy desires (one MD, the other WD). We were interested in whether children who attributed negative emotions to successful transgressors would be inclined to attribute positive emotion (e.g., relief) to a person who tried but failed to transgress.

\section{Method}

\section{Participants}

Children were recruited and run through the study at Boston-area preschools, summer camps, and two museum-based laboratory sites. A range of ethnic and socio-economic backgrounds was represented in the sample, but participants were predominantly White and from middle-class families.

Participating children ( $n=111$ ) included the following: (1) 233 -year-olds (14 females, $M_{\text {age }}=3.51, S D_{\text {age }}=.27$, age range in months: 36-46); (2) 454 -to 5-year-olds (29 females, $M_{\text {age }}=5.00, S D_{\text {age }}=.55$, age range in months: 50-71.8); and (3) 437 - to 9-year-olds (27 females, $M_{\text {age }}=8.43, S D_{\text {age }}=.87$, age range in months: 84.7-119.9). 


\section{Materials and procedures}

Each participant was interviewed about all four stories. Story character gender was always matched to participant gender, and story order was varied using a balanced Latin square design (see Appendix for text of stories).

A 4-point scale was used to collect emotion attribution data: (1) very sad, (2) a little sad, (3) a little bappy, and (4) very happy. The scale was represented by four faces that were labelled by the experimenter. During key scenes in the illustrated stories, the transgressors' facial features were omitted. Participants were forewarned about this and were told that this was done because 'your job is to tell us how the boy/girl feels, and we don't want to have a feeling already on his/her face'. None of the children expressed confusion about the rating scale or the blank faces.

\section{Material-desire stories}

The two MD stories each featured characters who wanted to obtain an object by pushing a peer. In all stories, characters' desires were made salient via the story text, thought bubbles, and comprehension checks ('What does Sarah want to do?'). In the MD-success story, the protagonist (1) wanted a playground swing, (2) pushed another child to get the swing, and (3) was shown on the swing while the victim was shown on the ground crying. In the MD-failure story, the protagonist (1) wanted a ball, (2) tried to push another child to get the ball, and (3) was shown missing with the push, leaving the other child to continue playing.

\section{Wicked-desire stories}

The two WD stories each featured characters who wanted to push a peer due to a feeling of dislike for the peer. In the WD-success story, the protagonist (1) wanted to push another child, (2) was shown pushing the other child, and (3) was shown standing while the victim was shown on the ground crying. In the WD-failure story, the protagonist (1) wanted to push another child, (2) was shown trying to push but missing, and (3) was shown standing while the intended victim continued playing.

The MD- and WD-success stories were modelled after the Yuill et al. study (1996) in which victims were described as hurt and crying. After each story, participants were asked the following questions about the main character (a male character is used as an example here):

1. How does Bill feel at the end of the story? [emotion rating scale used]

2. Why does Bill feel that way? [answer recorded verbatim via paper and pencil]

3. Does Bill have any other feelings? [If 'yes,' emotion rating scale used again]

4. [If 'yes' to \#3] Why does be feel that way? [answer recorded verbatim via paper and pencil]

\section{Scoring}

\section{Emotion attributions}

Using the emotion rating scale, all children provided an initial rating in each story. The main analyses of emotion attributions focused on children's initial emotion attributions to the transgressors.

Brief follow-up analyses were also conducted that incorporated children's responses to the question about other feelings. For any child who attributed two emotions to a 
character, a blended emotion score for that character was computed as the mean of the two emotion ratings (e.g., ratings of very happy (4) and a little sad (2) were averaged as $(4+2) / 2=3)$. This approach allowed us to capture a more nuanced score of how some children viewed emotions associated with transgression. When a child attributed only one feeling to a character, this was the child's emotion attribution score for that character.

\section{Mixed-emotion attributions}

Children were given credit for attributing mixed emotions to a transgressor only if two opposite-valence emotions were attributed to a character. The emotion rating scale was clearly divided by valence, making reliability checks on the scoring of children's mixed-emotion attributions unnecessary.

Justifications for emotion attributions

Children's justifications for their emotion attributions to the transgressors were categorized using a system similar to those used in related studies (e.g., Arsenio \& Kramer, 1992; Smith et al., 2010). The justifications were categorized as follows:

1. Desires: Responses focused on the desires of the transgressor (satisfied or frustrated). Examples: She's happy because she got the ball; He's sad because he missed the other boy.

2. Moral Concerns: Responses focused on harm, the act of victimization, or moral rules. Examples: He's sad because be hurt the boy; She's sad because she know it was wrong to act that way.

3. Sanctions: Responses focused on being caught or punished. Example: He's sad because be's afraid be'll get in trouble.

4. Relief: Responses focused - implicitly or explicitly - on happiness that no one was hurt or victimized (relevant in the MD- and WD-failure stories). Example: He's happy because the boy didn't get burt.

5. Other: Responses that could not be coded using the categories listed above. Example: I don't know.

Two raters separately coded 430 primary emotion attribution justifications using this system. Inter-rater reliability was high, kappa $=.89$; the discrepancies were resolved through discussion. One of the raters then coded the remainder of the primary and secondary emotion attributions.

\section{Results}

\section{Preliminary analyses}

All children remembered the protagonists' desires in each story at the first comprehension check. There were no effects of gender or story order; therefore, these variables were not included in the analyses reported below.

\section{Initial emotion attributions to transgressors}

First, children's initial emotion attributions to the transgressors were analysed. These data are displayed in Table 1 . As is clear in Table 1, across age groups and desire types, children attributed negative emotion to the unsuccessful transgressors. An initial 3 (age 
group) $\times 4$ (story type: WD-success; MD-success; WD-failure; MD-failure) mixed-measures ANOVA with accompanying Bonferroni-corrected post-boc analyses was run. These analyses confirmed three things. First, as a function of age, there were no differences in how the feelings of the two failed transgressors were viewed ( $\phi$-values ranged from .71 to 1.00). Second, there were no within-age-group differentiations between the emotions attributed to the unsuccessful MD and WD transgressors (all $p$-values $=1.00)$. Finally, in most cases, children attributed more positive emotions to successful transgressors compared with unsuccessful transgressors: 3-year-olds (MD transgressors $p<.001$ ); 4 - to 5-year-olds (WD transgressors $p<.001$; MD transgressors $p<.001$ ); and 7- to 9-year-olds (WD transgressors $p=.01$; MD transgressors $p<.001$ ). The notable exception to this was consistent with the hypotheses of the study: The 3-year-olds did not attribute significantly different emotions to the successful and unsuccessful characters with wicked desires, $p=.18$. Because children's emotion attributions to the successful transgressors were most central to the hypotheses of the study, this is the focus of the remaining analyses of emotion attributions.

A 3 (age group) $\times 2$ (story type: WD-success vs. MD-success) mixed-measures ANOVA was run on children's initial emotion attributions. Mean emotion attributions to the successful transgressors are displayed in Figure 1. There was a main effect of story type, $F$ $(1,108)=12.35, p<.001, \eta_{\mathrm{p}}^{2}=.10$. There was no main effect of age group $(p=.24)$, but there was a significant age group $\times$ story type interaction, $F(2,108)=4.00, p=.02$, $\eta_{\mathrm{p}}^{2}=.07$.

The age group $\times$ story type interaction was clarified with simple-effects analyses. As is evident in Figure 1, the significant interaction was fuelled by the 3-year-old group, which

Table I. Mean initial emotion attributions (with SDs) to transgressors as a function of age group and story type

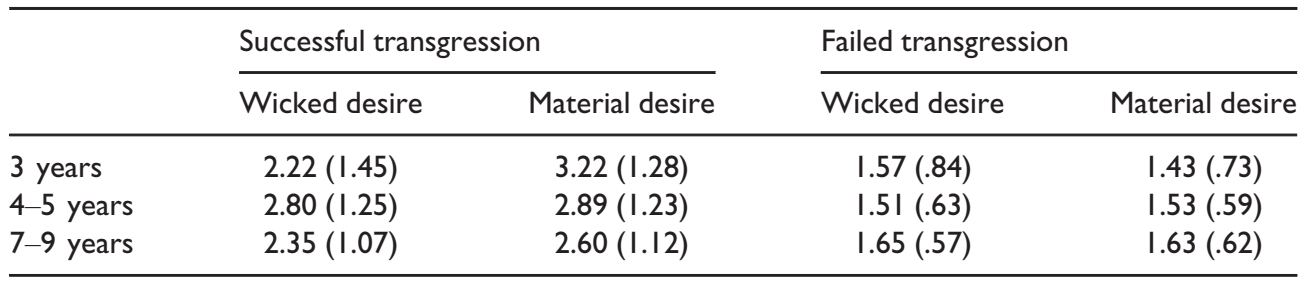

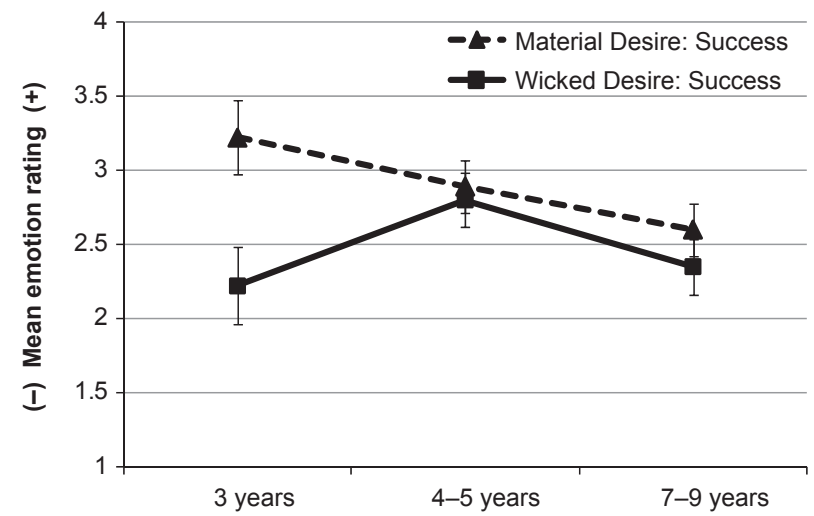

Figure I. Mean emotion attributions to the successful transgressors as a function of age group and story type (analysis with initial attribution scores only). 
attributed negative emotion in the WD-success story $(M=2.22)$ and positive emotion in the MD-success story $(M=3.22), F(1,108)=13.97, p<.001, \eta_{\mathrm{p}}^{2}=.12$. Neither the 4 - to 5-year-old group $[F(1,108)=.22, p=.64]$ nor the 8 - to 9-year-old group $[F(1$, $108)=1.71, p=.19$ ] discriminated between the two successful transgressors in this manner.

Finally, trend analyses were conducted. The emotions children attributed to the WD-success transgressor were, as a function of age group, best represented by a quadratic model ( $F$ for linear trend $=.17, p=.68 ; F$ for quadratic trend $=4.55, p=.04$ ). Conversely, the emotions children attributed to the MD-success transgressor were, as a function of age group, best represented by a linear model ( $F$ for linear trend $=3.93$, $p=.05 ; F$ for quadratic trend $=.01, p=.93$ ).

\section{Mixed-emotion attributions}

Table 2 displays the frequencies of mixed-emotion attributions. A McNemar test established that when all participants were considered, there was no difference in the frequency of attributing mixed emotions in the WD- compared with the MD-success stories, $p=.30$. Likewise, there was no difference in the frequency of mixed-emotion attributions across the WD- and MD-failure stories, $p=1.00$. There were, however, differences across the success and failure stories. Participants were more likely to attribute mixed emotions in the successful transgression stories than they were in the failure stories (WD-success vs. WD-failure $p=.02$; MD-success vs. MD-failure $p<.001$ ). As is clear from Table 2, this effect was largely driven by the 7-to 9-year-olds. Accordingly, mixed-emotion attributions were examined as a function of age group.

Low expected cell counts made the use of chi-square tests untenable in analyses that included all three age groups. A strategy to use two age groups was devised, based on well-established findings that children younger than 6 years of age frequently deny that others have mixed feelings (Harris, 1989). The two age groups used in the analyses of mixed-emotion attributions were 3- to 5-year-olds and 7- to 9-year-olds.

In the WD-success condition, the frequency of mixed-emotion attributions differed as a function of age, $\chi^{2}(1, N=111)=15.04, p<.001$; the 7 - to 9-year-olds were more likely than the 3- to 5-year-olds to attribute mixed feelings to the WD-success transgressor. The same was true in the MD-success condition, $\chi^{2}(1, N=111)=20.95, p<.001$, in the WD-failure condition, $\chi^{2}(1, N=111)=9.05, p<.01$, and in the MD-failure condition, $\chi^{2}(1, N=111)=4.42, p=.04$.

In sum, compared with the failed transgression stories, it was more common for mixed feelings to be attributed following the successful transgression stories. Further, the 7-to 9-year-old children were much more likely than the younger children to attribute mixed emotions to the protagonists following each of the four stories.

Table 2. Percentages of participants who provided mixed-emotion attributions as a function of age group and story type

\begin{tabular}{lcccccc}
\hline & \multicolumn{2}{l}{ Successful transgression } & & \multicolumn{2}{l}{ Failed transgression } & \\
\cline { 2 - 3 } & Wicked desire (\%) & Material desire (\%) & & Wicked desire (\%) & Material desire (\%) \\
\hline 3 years & 13 & 4 & & 0 & 4 \\
$4-5$ years & 11 & 20 & & 7 & 7 \\
$7-9$ years & 44 & 56 & & 23 & 19 \\
\hline
\end{tabular}




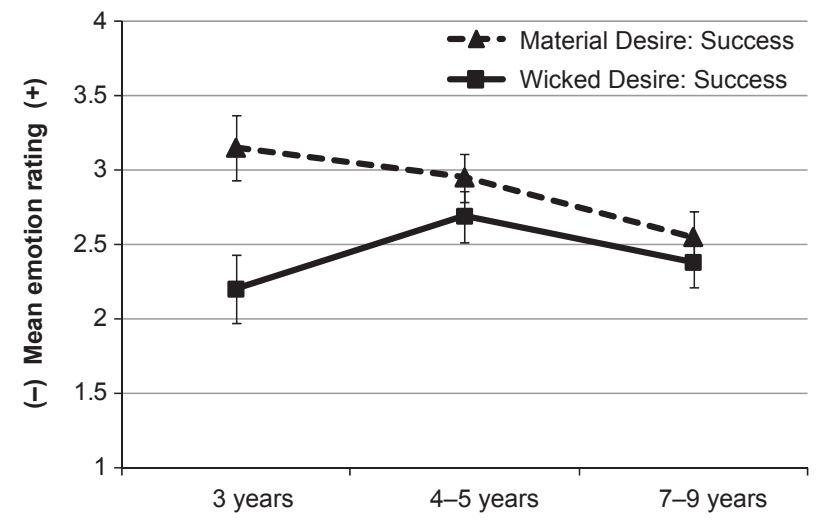

Figure 2. Mean emotion attributions to the successful transgressors as a function of age group and story type (analysis performed with blended primary and secondary emotion attributions).

Following the analysis of children's mixed-emotion attributions, children's blended emotion attributions were briefly explored. For a particular story character, a blended emotion score was computed as the mean of the primary and secondary emotions attributed by a child to that character. For a child who attributed only one emotion, this single rating served at the emotion score for that particular character.

As is evident in Figure 2, the results when using the blended emotion attributions were similar to those reported above. Trend analyses were run on the blended emotion attribution scores, and the results were the same as above: (1) the emotions children attributed to the WD-success transgressor were, as a function of age group, best represented by a quadratic model ( $F$ for quadratic trend $=3.46, p=.06$ ) and $(2)$ the emotions children attributed to the MD-success transgressor were, as a function of age group, best represented by a linear model ( $F$ for linear trend $=5.29, p=.02$ ).

\section{Justifications for emotion attributions}

Children's explanations for their emotion attributions were analysed next. All 111 children provided a verbal response when asked why they attributed a particular primary emotion in each of the four stories. Thus, there were 444 primary emotion attribution justifications available for coding. There were 105 secondary emotion attribution justifications available for coding, resulting in 549 emotion attribution justifications that required classification.

Very few of the justifications fell into the relief $(3 \% ; n=19)$ and sanctions $(<1 \% ; n=2)$ categories. By contrast, most were captured by the desires $(60 \% ; n=330)$ and moral concerns ( $23 \% ; n=129)$ categories. Roughly $13 \%(n=69)$ of the justifications were not codable. ${ }^{1}$ To create a more parsimonious classification system, the relief justifications were placed in the moral concerns category (concerns about victimization formed the basis for both types of responses). Because they comprised $<1 \%$ of the justifications, the sanctions responses were omitted from further analyses. Thus, the analyses reported

\footnotetext{
' In the analysis of justifications for primary emotion attributions, it was found that $64 \%$ of all 'Other' responses were provided by children in the 3-year-old group. The large majority of these other justifications by the 3-year-olds involved children saying 'I don't know'. This finding is consistent with other studies in which young children have been able to provide coherent responses without easily explaining those judgements (e.g., Baumard, Mascaro, \& Chevallier, 20I I).
} 
below focused on children's moral concerns and desires justifications. In a purely descriptive approach to the justification data, justifications for emotion attributions were classified using four categories: (1) mention of desires only; (2) mention of moral concerns only; (3) mention of both desires and moral concerns; and (4) no codable justification provided. Table 3 displays the frequencies of these justification types as a function of age and story type.

To resolve problems with low cell counts, (1) only codable justifications (listed as D, M, and D/M in Table 3) were subjected to formal analysis and (2) justifications that contained any references to moral concerns ( $\mathrm{M}$ and $\mathrm{D} / \mathrm{M}$ in Table 3 ) were combined into one category and were compared to desires-only justifications.

In the MD- and WD-failure conditions, the large majority of codable justifications - $84 \%$ and $91 \%$, respectively - focused solely on frustrated desires. A McNemar test established that children did not differ in the extent to which they used desires-only justifications across the WD- and MD-failure conditions $(p=.21)$. Further, the age groups did not differ in the extent to which they offered desires-only justifications in both the WD-failure condition, $\chi^{2}(2, N=88)=1.16, p=.56$, and in the MD-failure condition, $\chi^{2}(2$, $N=98)=3.39, p=.18$. Finally, a series of McNemar tests established that children offered significantly more desires-only justifications in response to the failed transgression scenarios compared with the successful transgression scenarios (all $p$-values $<.001$ ). The remaining justification analyses focus on the WD- and MD-success stories.

There was a significant association between age and justification type in the WD-success scenario, $\chi^{2}(2, N=100)=11.62, p<.01$. More of the 7 - to 9 -year-olds $(85 \%)$ mentioned moral concerns in the WD-success scenario compared with the 3-year-olds $\left[53 \% ; \chi^{2}(1, N=56)=6.32, p=.01\right]$ and the 4 - to 5-year-olds [52\%; $\chi^{2}(1$, $N=85)=10.72, p<.001]$. The two younger groups did not differ, $p=.94$.

A similar association between age group and justification type emerged in the MD-success scenario, $\chi^{2}(2, N=106)=17.27, p<.001$. More of the 7 - to 9-year-olds (77\%) mentioned moral concerns in the MD-success scenario compared with the 3 -year-olds $\left[22 \% ; \chi^{2}(1, N=61)=15.81, p<.001\right]$ and the 4 - to 5 -year-olds $\left[47 \% ; \chi^{2}(1\right.$, $N=88)=8.39, p<.01]$. The two younger groups did not differ, $p=.07$.

In sum, children of all ages focused on frustrated desires in the MD- and WD-failure stories. As expected, in the MD- and WD-success stories, the 7-to 9-year-old group was most likely to think about the transgressors' emotional responses in moral terms.

Table 3. Frequencies of justifications for emotion attributions as a function of age group and story type (expressed as percentages)

\begin{tabular}{|c|c|c|c|c|c|c|c|c|c|c|c|c|}
\hline & \multicolumn{4}{|c|}{3 years $(\%)$} & \multicolumn{4}{|c|}{$4-5$ years $(\%)$} & \multicolumn{4}{|c|}{ 7-9 years (\%) } \\
\hline & $\mathrm{D}$ & $M$ & $\mathrm{D} / \mathrm{M}$ & O & $\mathrm{D}$ & M & $D / M$ & O & $\mathrm{D}$ & $M$ & $\mathrm{D} / \mathrm{M}$ & O \\
\hline WD-S & 30 & 30 & 4 & 35 & 47 & 40 & II & 2 & 14 & 32 & 49 & J \\
\hline MD-S & 61 & 13 & 4 & 22 & 53 & 27 & 20 & 0 & 23 & 19 & 58 & 0 \\
\hline WD-F & 39 & 4 & 0 & 57 & 76 & 7 & 4 & 13 & 72 & 2 & 16 & 9 \\
\hline MD-F & 65 & 0 & 0 & 35 & 89 & 0 & 7 & 4 & 79 & 0 & 14 & 7 \\
\hline
\end{tabular}

Note. Story types abbreviated as: WD-S = wicked-desire success, MD-S = material-desire success, $\mathrm{WD}-\mathrm{F}=$ wicked-desire failure, $\mathrm{MD}-\mathrm{F}=$ material-desire failure. Justifications abbreviated as: $\mathrm{D}=$ desires only, $M=$ moral concerns only, $D / M=$ both desires and moral concerns mentioned, $\mathrm{O}=$ other (uncodable). Percentages were computed with the sanctions category omitted from analyses. Percentages are rounded to nearest whole number. 
Although the 3-year-olds saw the WD-success transgressor as feeling bad, they were often unable to explain their attributions of negative emotion. By contrast, the 3-year-olds were, by and large, able to explicitly connect the MD-success transgressor's positive emotions to satisfied desires.

\section{Discussion}

There are times when people commit moral violations to gain control of a valued resource, and there are other cases in which people commit moral violations solely in the service of inflicting physical or emotional pain (Baumeister, 1996). The goal of the present study was to ascertain how 3- to 9-year-old children expect others to feel after satisfying these two types of desires.

Our results show that 3-year-olds reason quite differently about the satisfaction of material-versus-wicked desires. Three-year-olds predicted that positive emotions would stem from material-desire satisfaction, and this tendency declined in linear fashion through age 9. This is consistent with the 2-step model described in the bulk of the happy-victimizer literature (e.g., Arsenio \& Kramer, 1992; Nunner-Winkler \& Sodian, 1988). When asked to predict the emotions that stem from wicked-desire satisfaction, the youngest and oldest children tended to attribute the most negative emotions, while the middle group (4- to 5-year-olds) was more inclined to attribute positive emotions. This is consistent with the inverted-U-shaped model described by Yuill et al. (1996). Thus, the present study provides a useful bridge across two sets of previously disconnected findings.

Why might 3-year-olds in particular differentiate between the two types of transgression when attributing emotion? We argue that children in this age group are inclined to focus tightly, in objective fashion, on the ultimate target of the desire. With this view of desires, in the WD-success scenario, a person wants and ends up with a problematic result (e.g., the hurting of a peer). In the MD-success case, a successful transgressor may cause harm, but attention is tightly focused on the fact that the transgressor wanted and ended up with something good.

One factor contributing to 3-year-olds' conceptions of wicked desires as objectively unpleasant may be the challenge of representing diverse mental states. Three-year-olds can easily grasp material desires; wanting an attractive object is a familiar desire for young children and young children are known to use aggression to control resources (Hay et al., 2011). However, 3-year-olds may not grasp that a person can harbour the desire to simply harm others; this is not a desire commonly expressed by young children. In response to a WD-success story, 3-year-olds may attribute negative emotion because the transgressor is experiencing a mental state that simply seems wrong or foreign.

Recent research on children's understanding of diverse desires complicates this account somewhat. Rakoczy et al. (2007) found that 3-year-olds appropriately attributed emotion to themselves and others in a task in which the child's own desire was mutually incompatible with someone else desire and only one party's desire was satisfied. However, while 3-year-olds have the capacity to accurately impute emotions to people whose desires conflict with their own, we argue that this feat is easier in some situations than in others. In the Rakoczy et al. (2007) study, the desires in question fell squarely within the personal domain (Nucci, 1981), where preferences and behaviours do not cause harm or injustice to others (as in the moral domain), injury to the self (the prudential domain), or disruptions to the flow of social life (the social-conventional domain; Smetana, 2006). The current study featured desires that resided in the moral domain. 
Young children appear to have difficulty grasping diverse desires in this particular domain, where children think in terms of rigid rights and wrongs (e.g., Nucci \& Turiel, 1993). Indeed, Wainryb and Ford (1998) showed that 5-year-olds have difficulty stating another person's unusual moral belief - a teacher's view that sharing unfairly was acceptable - even after the children were informed of the teacher's belief. Similarly, Conry-Murray (in press) found that 4-year-olds who had passed standard false-belief tasks had difficulty repeating the belief held by a teacher that biting others is okay. While Yuill et al. (1996) did find that 5-year-olds link happy feelings to the satisfaction of wicked desires when personal interests are made more salient than moral concerns, more research is needed to explore links between children's attributions of emotion and their ability to represent others' unusual moral beliefs.

Another factor that deserves attention in future research is the extent to which children's positivity biases and their capacity to represent others' wicked desires are related phenomena. Research on the positivity bias has shown that preschool-age children need several pieces of negative information about another person before they view that person in a negative light (Boseovski \& Lee, 2006). Similarly, 3- to 7-year-old children more readily make use of positive testimony about a new person, compared with negative testimony (Boseovski, 2011). It may be that especially for the youngest children in the present study, the information provided in the WD-success scenario was not rich enough to convince them that the WD-success character truly wanted to be aggressive.

Finally, the absence of contextual information in the present study may have masked many of the youngest children's insights into wicked desires. There is evidence that children are willing to predict antisocial action in the context of revenge (e.g., Posada \& Wainryb, 2008). Future studies should explore children's understanding of transgression and emotion when issues like revenge are introduced.

We note that children in the present study also saw characters attempting but failing to transgress. Most children attributed negative emotion in these cases. Even children who saw the WD-success transgressor as feeling bad predicted that the WD-failure transgressor would also feel bad. Failure to satisfy a desire of any type may cue an automatic attribution of negative emotion. This finding adds, in nuanced fashion, to related research. Lagattuta (2005) found that with increasing age, children become more likely to attribute pride to a character who wants transgress but exerts willpower to avoid a transgression attempt. By contrast, the present study showed characters actively attempting to transgress but failing. Given this, it is possible that older children may be especially likely to differentiate situations in which a person wants to transgress and fails versus situations in which a person wants to transgress and refrains.

\section{Conclusion}

We found that 3-year-old children attribute negative emotion to a person who satisfies a wicked desire to victimize others and positive emotion to a person who victimizes others to fulfil a material desire. These results bridge a number of existing studies on the development of emotion understanding in the moral realm (e.g., Nunner-Winkler \& Sodian, 1988; Yuill et al., 1996) and paint a more complete picture of how very young children represent the relationship between desire and emotion. Our findings highlight the need to consider multiple aspects of context (e.g., target of desires, nature of social domain) when characterizing the development of mental-state understanding. 


\section{Acknowledgements}

The authors wish to thank Lisa Burns, Deborah Anderson, Anna Straussberger, and Eroica Rene for their help with data collection. We also thank Paul Harris, Henry Wellman, and Meredith Meyer for feedback on a draft of this article. We are grateful to the Boston Museum of Science, the Boston Children's Museum, Camp Kaleidoscope, Garden Nursery School, The Children's Coop, and Drumlin Farm Community Preschool for serving at research sites for this study. Finally, we thank the parents and children who took part in this research. Work on this research by C.E.S was supported, in part, by Award Number T32HD007109 from the Eunice Kennedy Shriver National Institute of Child Health \& Human Development.

\section{References}

Arsenio, W. F., Gold, J., \& Adams, E. (2006). Children's conceptions and displays of moral emotions. In M. Killen \& J. G. Smetana (Eds.), Handbook of moral development (pp. 581-609). Mahwah, NJ: Lawrence Erlbaum.

Arsenio, W. F., \& Kramer, R. (1992). Victimizers and their victims: Children's conceptions of the mixed emotional consequences of moral transgressions. Child Development, 63, 915-927. doi: $10.2307 / 1131243$

Bartsch, K., \& Wellman, H. M. (1995). Children talk about the mind. New York, NY: Oxford University Press.

Baumard, N., Mascaro, O., \& Chevallier, C. (2011). Preschoolers are able to take merit into account when distributing goods. Developmental Psychology. Advance online publication. doi:10. $1037 / \mathrm{a} 0026598$

Baumeister, R. F. (1996). Evil: Inside buman cruelty and violence. New York, NY: W H Freeman/ Times Books/Henry Holt.

Boseovski, J. J. (2011). Trust in testimony about strangers: Young children prefer reliable informants who make positive attributions. Journal of Experimental Child Psychology, 111, 543-551. doi:10.1016/j.jecp.2011.10.008

Boseovski, J. J., \& Lee, K. (2006). Children's use of frequency information for trait categorization and behavioral prediction. Developmental Psychology, 42, 500-513. doi:10.1037/0012-1649.42.3. 500

Conry-Murray, C. (in press). Young children's understanding of beliefs about moral and conventional rule violations. Merrill-Palmer Quarterly.

Harris, P. L. (1989). Children and emotion: The development of psychological understanding. Cambridge, MA: Blackwell.

Hay, D. F., Hurst, S., Waters, C. S., \& Chadwick, A. (2011). Infants' use of force to defend toys: The origins of instrumental aggression. Infancy, 16, 471-489. doi:10.1111/j.1532-7078.2011. 00069.x

Keller, M., Lourenço, O., Malti, T., \& Saalbach, H. (2003). The multifaceted phenomenon of 'happy victimizers': A cross-cultural comparison of moral emotions. British Journal of Developmental Psychology, 21, 1-18. doi:10.1348/026151003321164582

Lagattuta, K. (2005). When you shouldn't do what you want to do: Young children's understanding of desires, rules, and emotions. Child Development, 76, 713-733. doi:10.1111/j.1467-8624. 2005.00873.x

Lourenço, O. (1997). Children's attributions of moral emotions to victimizers: Some data, doubts and suggestions. British Journal of Developmental Psychology, 15, 425-438. doi:10.1111/j. 2044-835X.1997.tb00739.x

Murgatroyd, S. J., \& Robinson, E. J. (1993). Children's judgments of emotion following moral transgression. International Journal of Behavioral Development, 16, 93-111.

Nucci, L. (1981). Conceptions of personal issues: A domain distinct from moral or societal concepts. Child Development, 52, 114-121. doi:10.2307/1129220 
Nucci, L., \& Turiel, E. (1993). God's word, religious rules, and their relation to Christian and Jewish children's concepts of morality. Child Development, 64, 1475-1491. doi:10.2307/1131547

Nunner-Winkler, G., \& Sodian, B. (1988). Children's understanding of moral emotions. Child Development, 59, 1323-1328. doi:10.2307/1130495

Posada, R., \& Wainryb, C. (2008). Moral development in a violent society: Colombian children's judgments in the context of survival and revenge. Child Development, 79, 882-898. doi:10. $1111 / j .1467-8624.2008 .01165 . x$

Rakoczy, H., Warneken, F., \& Tomasello, M. (2007). 'This way!', 'No! That way!' - 3-year olds know that two people can have mutually incompatible desires. Cognitive Development, 22, 47-68. doi:10.1016/j.cogdev.2006.08.002

Smetana, J. G. (1981). Preschool children's conceptions of moral and social rules. Child Development, 52, 1333-1336. doi:10.2307/1129527

Smetana, J. G. (2006). Social-cognitive domain theory: Consistencies and variations in children's moral and social judgments. In M. Killen \& J. G. Smetana (Eds.), Handbook of moral development (pp. 119-153). Mahwah, NJ: Lawrence Erlbaum.

Smith, C. E., Chen, D., \& Harris, P. L. (2010). When the happy victimizer says sorry: Children's understanding of apology and emotion. British Journal of Developmental Psychology, 28, 727 746. doi:10.1348/026151009X475343

Symons, D. K., Fossum, K. M., \& Collins, T. (2006). A longitudinal study of belief and desire state discourse during mother-child play and later false belief understanding. Social Development, 15, 676-691. doi:10.1111/j.1467-9507.2006.00364.x

Wainryb, C., \& Ford, S. (1998). Young children's evaluations of acts based on beliefs different from their own. Merrill-Palmer Quarterly, 44, 484-503.

Wellman, H. M., \& Liu, D. (2004). Scaling of theory-of-mind tasks. Child Development, 75, 523-541. doi:10.1111/j.1467-8624.2004.00691.x

Wintre, M., \& Vallance, D. D. (1994). A developmental sequence in the comprehension of emotions: Intensity, multiple emotions, and valence. Developmental Psychology, 30, 509-514. doi:10. 1037/0012-1649.30.4.509

Yuill, N., Perner, J., Pearson, A., Peerbhoy, D., \& van den Ende, J. (1996). Children's changing understanding of wicked desires: From objective to subjective and moral. British Journal of Developmental Psychology, 14, 457-475. doi:10.1111/j.2044-835X.1996.tb00718.x

Received I May 20 I3; revised version received II July 2013

\section{Appendix: Full Text of Stories (Girls' Version Presented Here) MD-success story}

(1) Sarah is on the playground at school. She sees that a girl in a yellow shirt is walking over to use the swing. (2) Sarah really wants to get on the swing. (3) Sarah pushes the girl in yellow. (4) The girl in yellow falls down and hurts her arm and cries and Sarah gets the swing.

\section{WD-success story}

(1) Kim is at school. She sees a girl in a blue shirt. Kim does not like the girl in blue. (2) Kim really wants to push the girl in blue and make her fall down. (3) Kim pushes the girl in blue.

(4) The girl in blue falls down and hurts her leg and cries. 


\section{MD-failure story}

(1) Emily is at school. She sees a girl in a red shirt playing with a ball. (2) Emily really wants to play with that ball. (3) Emily tries to push the girl in red and take the ball, but she misses. (4) And the girl in red just keeps playing with the ball.

\section{WD-failure story}

(1) Lara is at school. She sees a girl in a green shirt. Lara does not like the girl in green. (2) Lara really wants to push the girl in green and make her fall down. (3) Lara tries to push the girl in green, but she misses. (4) And the girl in green just keeps playing. 